\title{
Correlations between nerve function and tissue oxygenation in diabetic patients: further clues to the aetiology of diabetic neuropathy?
}

\author{
M.J.Young, A. Veves, M. G. Walker and A.J. M. Boulton \\ Manchester Royal Infirmary, Manchester, UK
}

\begin{abstract}
Summary. Transcutaneous oxygen, laser Doppler flowmetry, peroneal nerve motor conduction velocity and skin temperature were assessed in both legs of 34 diabetic patients, who had a mean age of 41 (range 29-77) years, and diabetes duration of 21 (3-34) years. Transcutaneous oxygen significantly correlated with peroneal nerve motor conduction velocity $(r=0.59 p<0.001)$ and laser Doppler flowmetry $(r=0.7$ $p<0.001)$. Laser Doppler flowmetry correlated weakly with peroneal motor conduction velocity, $(r=0.34 p<0.05)$. In each patient the leg with the higher transcutaneous oxygen (mean $70.2 \pm 9.3$ (SD) $\mathrm{mmHg}$ ) had a significantly higher peroneal motor conduction velocity $(45.3 \pm 7.1$ vs $41.5 \pm$ $6.3 \mathrm{~m} / \mathrm{s}, p<0.01$ ), than the leg with the lower transcutaneous oxygen $(61.0 \pm 11.9 \mathrm{~mm} \mathrm{Hg})$, though no difference in skin temperature was observed, $31.4 \pm 0.4$ vs $31.1 \pm 0.5^{\circ} \mathrm{C}$. We then assessed the potential for reversibility of conduction velocity deficits in ten non-diabetic patients, aged 59 (5277) years, undergoing unilateral femoro-popliteal bypass,
\end{abstract}

measuring transcutaneous oxygen, peroneal nerve motor conduction velocity and skin temperature pre- and 6 weeks post-surgery. In the control leg (unoperated) there was no significant change in transcutaneous oxygen ( $63.2 \pm 8.8$ vs $63.0 \pm 4.6 \mathrm{~mm} \mathrm{Hg}$ ), peroneal nerve motor conduction velocity $(45.1 \pm 7.8$ vs $43.4 \pm 7.2 \mathrm{~m} / \mathrm{s})$ or skin temperature $\left(30.8 \pm 1.3\right.$ vs $\left.30.2 \pm 1.2^{\circ} \mathrm{C}\right)$ after surgery (all NS). In the operated leg, transcutaneous oxygen increased from $59.3 \pm 10.7$ to $70.7 \pm 7.2 \mathrm{~mm} \mathrm{Hg}(p<0.01)$, and peroneal nerve motor conduction velocity from $42.6 \pm 6.1$ to $46.7 \pm 3.2 \mathrm{~m} / \mathrm{s}(p<0.01)$, but skin temperature was unchanged $30.3 \pm 0.4$ vs $30.4 \pm$ $1.3^{\circ} \mathrm{C}$ (NS). These studies provide further evidence that peripheral nerve function is associated with tissue hypoxia and that improving tissue oxygenation can significantly improve nerve conduction over a short period of time.

Key words: Diabetes mellitus, peripheral neuropathy, tissue oxygenation, peripheral vascular disease.
The aetiopathogenesis of diabetic peripheral neuropathy has been the subject of considerable debate, between those who believe that metabolic abnormalities $[1,2]$, including those of the polyol pathway [3], are the principal cause and those who favour microvascular disease $[4,5]$. Both mechanisms are likely to be at work in a single individual, and indeed the two may be related $[2,4]$.

In addition to work in experimental diabetes [6-9], there is evidence from a variety of sources that microvascular pathology plays a role in human diabetic neuropathy. Biopsies of sural nerve taken from neuropathic diabetic patients show features of a microangiopathy, including basement membrane thickening and endothelial hyperplasia [10]. Similar pathological and electrophysiological features to those seen in diabetic patients can be found in patients with hypoxic chronic obstructive airways disease [11-13]. Direct measurement of endoneurial oxygen tensions has shown that diabetic sural nerve is hypoxic compared to non-diabetic controls [14]. It has re- cently been demonstrated that whilst nerve conduction velocity increases following exercise in non-diabetic and non-neuropathic diabetic subjects, it fails to increase in diabetic patients with neuropathy, and this is believed to be due to impairment of neural blood flow [15].

Direct measurement of transcutaneous oxygen $\left(\mathrm{TcPO}_{2}\right)$ has been used as an index of peripheral perfusion for peripheral vascular disease [16] and to predict ulcer healing [17]. In this study transcutaneous oxygen, skin temperature and peroneal nerve motor conduction velocity (MCV), which is the best correlate of structural pathology in early diabetic neuropathy [18], were measured in diabetic patients in order to assess whether a direct relationship existed.

In a parallel study, non-diabetic patients undergoing unilateral femoro-popliteal bypass were examined before and after surgery to assess whether revascularisation could improve nerve function. These results may provide a guide to future therapeutic options in diabetic patients. 


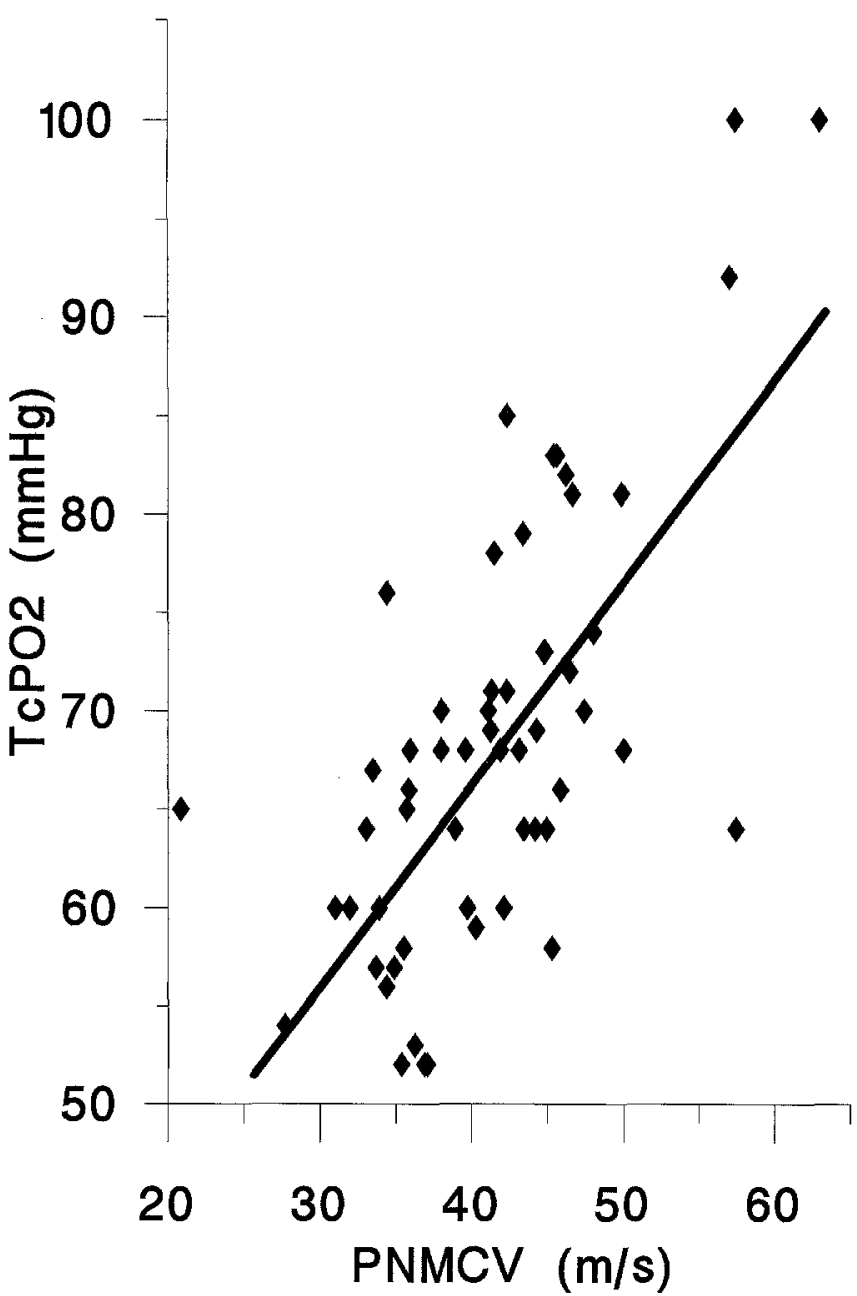

Fig. 1. Transcutaneous oxygen $\left(\mathrm{TcPO}_{2}\right)$ vs peroneal nerve motor conduction velocity (PNMCV) $(r=0.59 p<0.001)$

\section{Patients and methods}

The studies were performed with the approval of the Manchester Central Hospitals NHS Trust Ethical Committee and all patients gave informed consent prior to participation.

The first study included 34 diabetic patients, 18 female, 24 with Type 1 (insulin-dependent) diabetes, mean age 41 (range 2977) years, with a mean duration of diabetes of 21 (3-34) years. Patients were selected to include those both with and without clinical neuropathy. None had clinical evidence of peripheral vascular disease or diabetic retinopathy as detected by fundoscopy through dilated pupils. All patients performed overnight urine collections prior to the study and had urine albumin excretion rates of less than $20 \mu \mathrm{g} / \mathrm{min}$.

$\mathrm{TcPO}_{2}$, peroneal nerve MCV, laser Doppler flowmetry and skin temperature were assessed in both legs. All measurements were made with the subject semi-recumbent on a couch in a warm room, with the temperature maintained above $25^{\circ} \mathrm{C}$. $\mathrm{TcPO}_{2}$ was measured using a TINA TCM3 meter, (Radiometer, Copenhagen, Denmark) at $44^{\circ} \mathrm{C}$ on the dorsum of the foot over the muscle extensor digitorum brevis (EDB). The electrode was left in place for $20 \mathrm{~min}$ and a stable reading of more than $1 \mathrm{~min}$ after this time was used for the analysis. The within subject coefficient of variation for this test which was assessed by measuring one subject daily for 10 days, was $2.4 \%$.

Peroneal nerve MCV was measured with standard surface electrodes with stimulation at the head of the fibula and on the shin, 10$15 \mathrm{~cm}$ above the ankle, with the recording electrode over the EDB and the earth electrode positioned mid-calf. A Medelec Neurostar electrophysiology system (Medelec Limited, Woking, UK) was used for all measurements. Tracings were taken of the motor action potentials and the latencies were measured by an independent observer who did not know the subject's identity or oxygen measurement.

Skin temperature was measured using a Mikron Infra-Red thermometer (Mikron Instrument Company, Inc., Wyckoff, NJ, USA) on the dorsum of each foot over the belly of EDB, after $30 \mathrm{~min}$ equilibration with room temperature. A mean of three readings was taken at each site. The within subject coefficient of variation was measured at $3 \%$.

Laser Doppler flowmetry was measured at $44^{\circ} \mathrm{C}$ with a Periflux PF3 laser Doppler perfusion monitor (Perimed, Stockholm, Sweden) immediately after measurement of $\mathrm{TcPO}_{2}$ and at the same site. The measurement was made using the standard Perimed perpendicular probe and holder, the probe was set at $12 \mathrm{kHz}$ bandwidth. The within subject coefficient of variation was $17 \%$.

In the second study, $\mathrm{TcPO}_{2}$, peroneal nerve $\mathrm{MCV}$ and skin temperature were measured in both legs of 10 consecutive non-diabetic patients, aged $59(52-77)$ years, with angiographically proven superficial femoral artery thromboses suitable for unilateral femoro-popliteal bypass. Measurements were made the day before and between 6 and 8 weeks following surgery, using the techniques outlined above. In all patients fasting plasma glucose measurements were performed on the day of operation and all were less than $6 \mathrm{mmol} / \mathrm{l}$.

\section{Statistical analysis}

All the results were analysed using Minitab Software (Minitab Inc., State College, $\mathrm{Pa}$, USA). The diabetic groups were compared using Student's $t$-test and the non-diabetic groups with a paired Wilcoxon test.

\section{Results}

\section{Study one: diabetic patients}

In the diabetic patients peroneal nerve MCV correlated with $\mathrm{TcPO}_{2}, r=0.59 p<0.001$ (Fig. 1), but not with skin temperature, $r=0.16$ (NS). There were no significant differences between Type 1 (insulin-dependent) and Type 2 (non-insulin-dependent) patients.

In each patient the leg with the higher $\mathrm{TcPO}_{2}$ (mean $70.2 \pm 9.3(\mathrm{SD}) \mathrm{mm} \mathrm{Hg}$ ) had a significantly higher peroneal MCV $(45.3 \pm 7.1 \mathrm{vs} 41.5 \pm 6.3 \mathrm{~m} / \mathrm{s}, p<0.01)$, than the leg with the lower $\mathrm{TcPO}_{2}(61.0 \pm 11.9 \mathrm{~mm} \mathrm{Hg})$, though no difference in skin temperature was observed, $31.4 \pm 0.4$ vs $31.1 \pm 0.5^{\circ} \mathrm{C}$.

The mean laser Doppler flux was $57.0 \pm 38.4$ perfusion units. Laser Doppler flux correlated with $\mathrm{TcPO}_{2}, r=0.7$, $p<0.001$ (Fig.2). Laser Doppler flux correlated with peroneal MCV, $r=0.34$, but this was significant at the $p<0.05$ level only.

\section{Study two: non-diabetic vascular patients}

In the operated leg $\mathrm{TcPO}_{2}$ increased from $59.3 \pm$ $10.7 \mathrm{~mm} \mathrm{Hg}$ pre-operatively to $70.7 \pm 7.2 \mathrm{~mm} \mathrm{Hg}$ postoperatively $(p<0.01)$. Peroneal nerve MCV increased from $42.6 \pm 6.1$ to $46.7 \pm 3.2 \mathrm{~m} / \mathrm{s}(p<0.01)$, but skin temperature was unchanged $30.3 \pm 0.4$ vs $30.4 \pm 1.3^{\circ} \mathrm{C}(\mathrm{NS})$. 


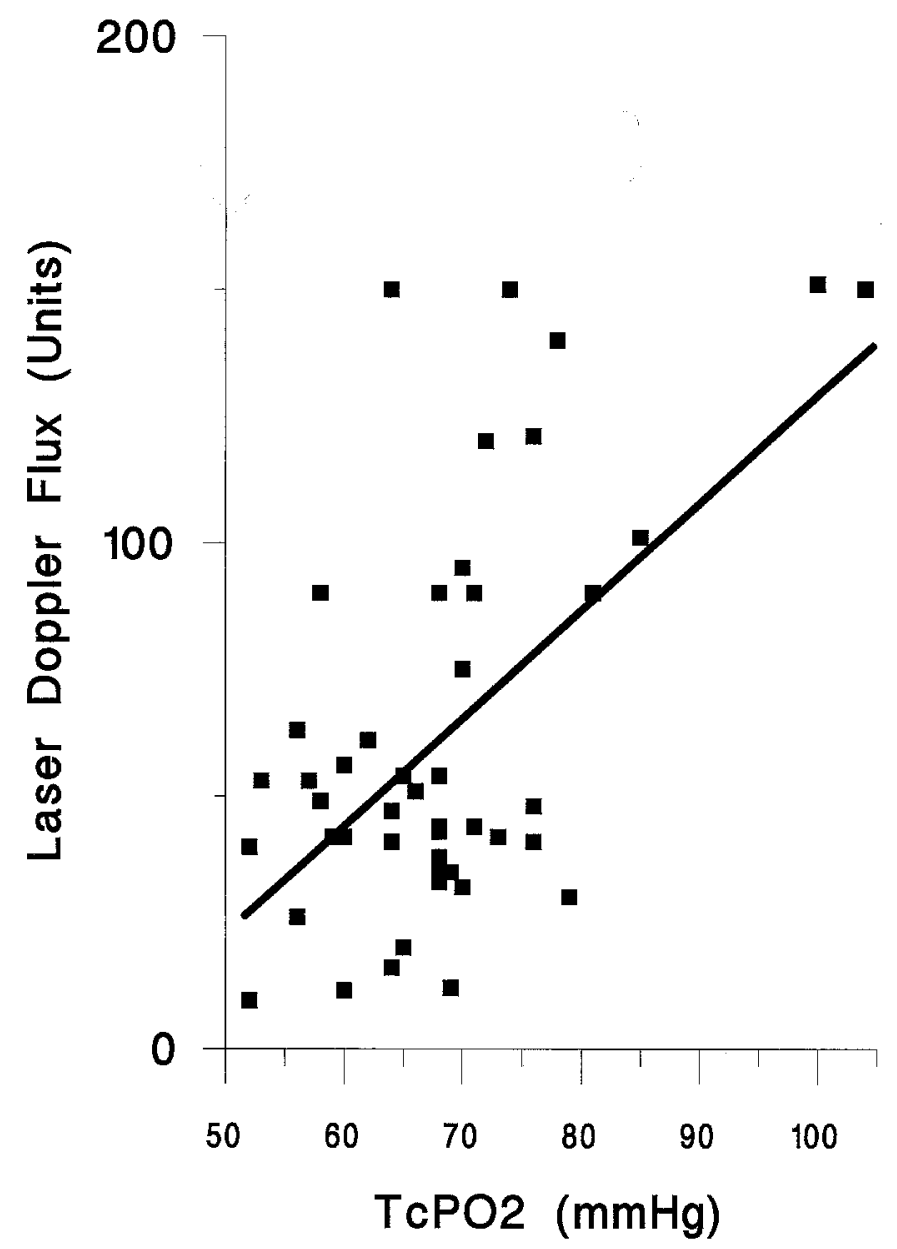

Fig. 2. Laser Doppler flux vs transcutaneous oxygen $\left(\mathrm{TcPO}_{2}\right)(r=0.7$ $p<0.001)$

There was no difference in $\mathrm{TcPO}_{2} 63.2 \pm 8.8$ vs $63.0 \pm$ $4.6 \mathrm{~mm} \mathrm{Hg}$, peroneal nerve MCV $45.1 \pm 7.8$ vs $43.4 \pm$ $7.2 \mathrm{~m} / \mathrm{s}$ or skin temperature $30.8 \pm 1.3$ vs $30.2 \pm 1.2^{\circ} \mathrm{C}$ (all NS) in the unoperated leg (Figs. 3 and 4).

\section{Discussion}

The evidence that microvascular flow and endoneurial hypoxia are implicated in the development of peripheral neuropathy is increasing in both animal and human studies [4-15]. Neuropathy can be prevented in experimental diabetes in rats by treatment with vasodilators from the induction of diabetes [8], and direct measurement of nerve blood flow has confirmed that this is reduced in diabetic rats [9]. Non-diabetic rats kept in a low oxygen environment have also been shown to develop peripheral neuropathy [19]. Recent research has also demonstrated that a surgically created proximal arterio-venous shunt can significantly reduce nerve function in the limb by reducing distal blood flow [6].

In man, direct measurement of endoneurial oxygen tension has shown that diabetic sural nerve is hypoxic compared to non-diabetic controls [14] and biopsies of sural nerve taken from neuropathic diabetic patients show features of microangiopathy [10]. Similar features can be found in biopsies from patients with hypoxic chronic obstructive airways disease [11], up to $20 \%$ of whom may develop peripheral neuropathy [12]. These patients also show the same electrophysiological features as diabetic patients, including resistance to ischaemic conduction failure [11]. A reduction in MCV and morphological abnormalities, including a reduction in myelinated fibre density have been reported in patients with peripheral vascular disease [20]. The creation of arterio-venous shunts for haemodialysis has been demonstrated to lead to distal neuropathy in a number of case reports [21-23]. Whilst an increase in peroneal $\mathrm{MCV}$ is seen in non-neuropathic diabetic, and non-diabetic subjects following exercise, which might be expected to improve limb blood flow, it has been demonstrated that nerve conduction velocity fails to increase in diabetic patients with neuropathy, suggesting impairment of neural blood flow [15]. The clear relationship between tissue oxygenation and nerve function observed in this study supports the view that hypoxia is implicated in the aetiopathogenesis of peripheral neuropathy. This, however, would apparently contrast with other studies which have shown that blood flow in the neuropathic diabetic foot is actually increased [24]. In these studies there is considerable evidence of arteriovenous shunting [25], including a high oxygen concentration in dorsal foot veins [26]. Arterio-venous shunting has also been demonstrated in the blood supply of the sural nerve of diabetic patients with neuropathy [27] and it is likely that the lower skin oxygen tensions measured in this study reflect shunts away from nutritive flow, which is also suggested by the weaker correlation between laser Doppler and peroneal MCV.

The absence of a direct correlation between changes in temperature and nerve function is probably related to the fact that in this study subjects were allowed to rest in a warm room before the readings were made, and this is likely to reduce the effects of a cool limb on peroneal MCV. It is also possible that the auto-sympathectomy described in these patients [28] removes the association between temperature and blood flow in diabetic patients.

It could be reasoned that if diabetic peripheral neuropathy is due in part to impaired endoneurial blood flow then reduction in blood flow or tissue oxygenation alone should result in peripheral nerve dysfunction. This is supported by the reports of peripheral neuropathy in patients with hypoxic chronic obstructive airways disease [12], morphological changes in the sural nerve of patients with peripheral vascular disease [20] and the observations of the effects of proximal shunts described above [6,21-23]. The present study examined non-diabetic patients with unilateral femoral artery thromboses undergoing reconstructive surgery, which allowed the unoperated leg to act as a control for other variables such as smoking or drugs and could provide a model for the role of impaired blood flow alone. The marked increase in tissue oxygenation following surgery was accompanied by a significant rise in peroneal conduction velocity in contrast to the findings of a previously published study by Hunter et al. [29]. However, in this previous study, there were mixed groups of diabetic and non-diabetic patients and the degree of vas- 


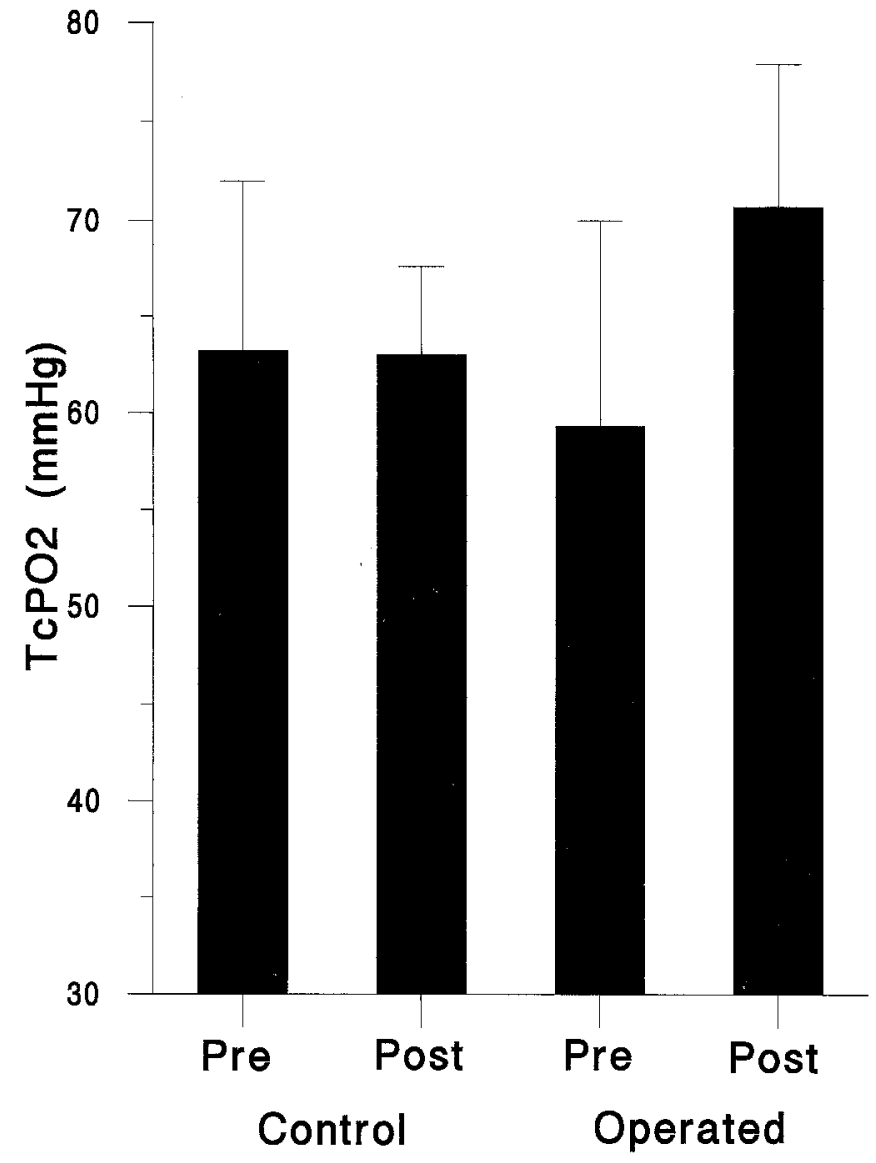

Fig.3. Mean (+SD) transcutaneous oxygen $\left(\mathrm{TcPO}_{2}\right)$ recordings pre- and post-surgery in the control and operated legs

cular impairment was greater, with one-half of the femoro-popliteal reconstructions being performed for limb salvage, at which stage irreversible changes are likely to have occurred.

The absence of significant rise in skin temperature in the non-diabetic group following reconstructive arterial surgery may reflect the 30 min or more of equilibration in a warm room that was allowed before the measurements were taken.

Although not significant in these relatively small numbers of patients there was a fall in $\mathrm{TcPO}_{2}$, peroneal nerve $\mathrm{MCV}$ and skin temperature in the control leg following surgery. This may reflect a form of steal phenomenon as peripheral vascular disease is usually bilateral, although asymmetrical, and the side of the bypass operation is determined by clinical indications.

In conclusion, these studies demonstrate that there is a significant relationship between tissue oxygenation and peripheral nerve function in diabetic patients and that in non-diabetic patients, improvement of tissue oxygenation is accompanied by a significant improvement in nerve function. These findings lend support to the hypothesis that endoneurial hypoxia is implicated in the aetiopathogenesis of diabetic peripheral neuropathy and that therapeutic strategies to improve blood flow, particularly in early neuropathy should be considered.

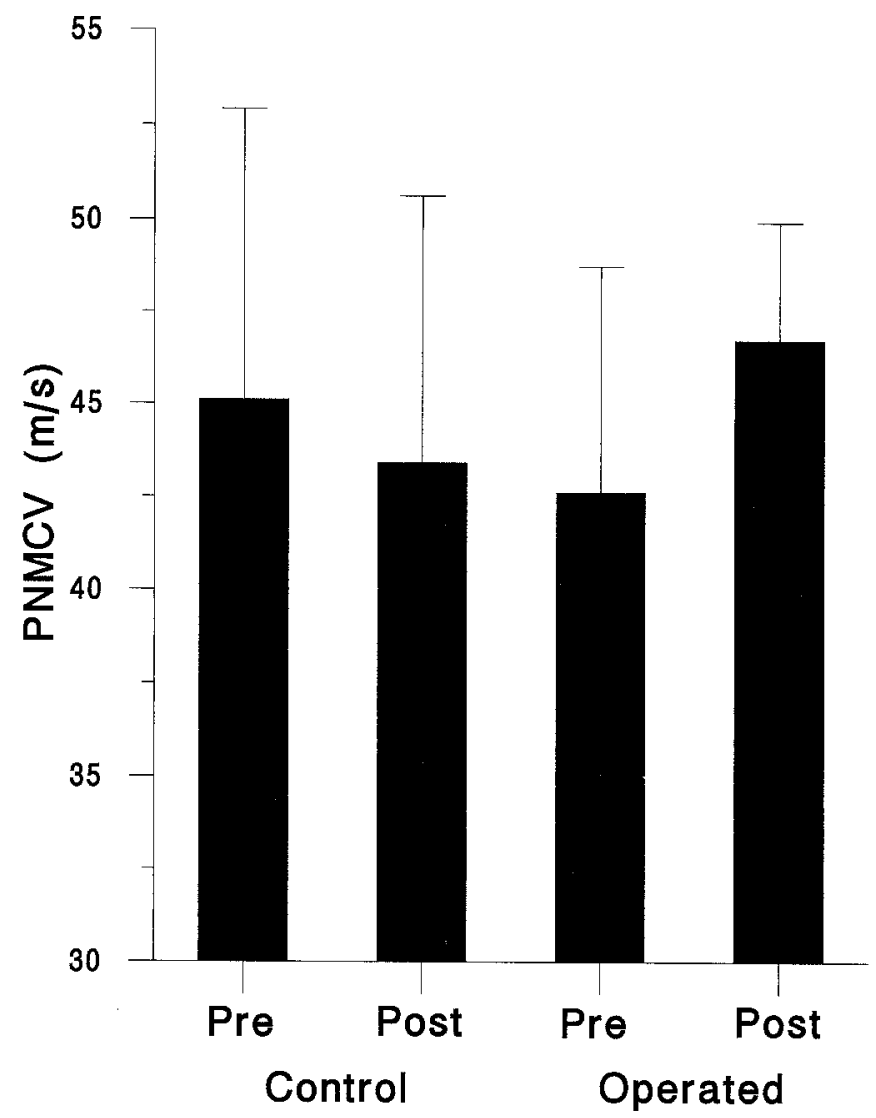

Fig.4. Mean ( + SD) peroneal motor conduction velocity (PNMCV) pre- and post-surgery in the control and operated legs

Acknowledgements. Dr. M. Young is supported by a grant from the Peter Kershaw Trust. We would like to thank Convatec UK, Wound Healing Research Institute, Deeside, Clwyd, for the loan of the transcutaneous oxygen and laser Doppler monitors.

\section{References}

1. Clements RS, Bell DSH (1982) Diagnostic, pathogenetic and therapeutic aspects of diabetic neuropathy. Special Topics Endocrinol Metab 2: 1-42

2. Bays HE, Pfeifer MA (1988) Peripheral diabetic neuropathy. Med Clin North Am 72: 1439-1464

3. Greene DA, Lattimer SA, Sima AAF (1988) Are disturbances of sorbitol, phosphoinositide, and $\mathrm{Na}+\mathrm{K}+$-ATPase regulation involved in pathogenesis of diabetic neuropathy? Diabetes 37 : 688-693

4. Low PA (1987) Recent advances in the pathogenesis of diabetic neuropathy. Muscle Nerve 10: 121-128

5. Dyck PJ (1989) Hypoxic neuropathy: does hypoxia play a role in diabetic neuropathy? Neurology 39: 111-118

6. Sladky JT, Tschoepe RL, Greenberg JH, Brown MJ (1991) Peripheral neuropathy after chronic endoneurial ischaemia. Ann Neurol 29:272-278

7. Cameron NE, Cotter MA, Robertson S (1989) Chronic low frequency electrical activation for one week corrects nerve conduction velocity deficits in rats with diabetes of three months duration. Diabetologia 32: 759-761

8. Cameron NE, Cotter MA, Robertson S (1992) Angiotensin converting enzyme inhibition prevents development of muscle and nerve dysfunction and stimulates angiogenesis in streptozotocindiabetic rats. Diabetologia 35: 12-18 
9. Cameron NE, Cotter MA, Low PA (1992) Nerve blood flow in early experimental diabetes in rats: relation to conduction deficits. Am J Physiol 261: E1-E8

10. Malik RA, Newrick PG, Sharma AK et al. (1989) Microangiopathy in human diabetic neuropathy: relationship between capillary abnormalities and the severity of neuropathy. Diabetologia 32: $92-102$

11. Malik RA, Masson EA, Sharma AK et al. (1990) Hypoxic neuropathy: relevance to human diabetic neuropathy. Diabetologia 33: 311-318

12. Nowak D, Bruch M, Arnaud F et al. (1990) Peripheral neuropathies in patients with chronic obstructive pulmonary disease: a multicenter prevalence study. Lung 168: 43-51

13. Masson EA, Church SE, Woodcock AA, Hanley SP, Boulton AJM (1988) Is resistance to ischaemic conduction failure induced by hypoxia? Diabetologia 31:762-765

14. Newrick PG, Wilson AJ, Jakubowski J, Boulton A.JM, Ward JD (1986) Sural nerve oxygen tension in diabetes. Br Med J 293: 1053-1054

15. Tesfaye S, Harris ND, Wilson RM, Ward JD (1992) Exercise-induced conduction velocity increment: a marker of impaired peripheral nerve blood flow in diabetic neuropathy. Diabetologia 35: 155-159

16. Hauser CJ, Klein SR, Mehringer M, Appel P, Shoemaker WC (1984) Assessment of perfusion in the diabetic foot by regional transcutaneous oximetry. Diabetes 33: 527-531

17. Pecoraro RE, Ahroni JH, Boyko EJ, Stensel VL (1991) Chronology and determinants of tissue repair in diabetic lower-extremity ulcers. Diabetes 40: 1305-1313

18. Veves A, Malik RA, Lye RH et al. (1991) The relationship between sural nerve morphometric findings and measures of peripheral nerve function in mild diabetic neuropathy. Diabetic Med 8: 917-921

19. Low PA, Schmelzer JD, Ward KK, Yao JK (1986) Experimental chronic hypoxic neuropathy: relevance to diabetic neuropathy. Am J Physiol 250: E94-E99

20. Rodriguez-Sanchez C, Sanchez MM, Malik RA, Ah-See AK, Sharma AK (1991) Morphological abnormalities in the sural nerve from patients with peripheral vascular disease. Histol Histopath 6: 63-71

21. Wilbourn AJ, Furlan AJ, Hulley W, Ruschhuap TW (1983) Ischaemic monomelic neuropathy. Neurology 33: 447-451

22. Knezevic W, Mastalgia FL (1984) Neuropathy associated with Bresica-Cimino arteriovenous fistulas. Arch Neurol 41: 1184 1192

23. Riggs JE, Moss AH, Labosky DA et al. (1989) Upper extremity ischaemic monomelic neuropathy: a complication of vascular access procedures in uremic diabetic patients. Neurology 39: 997-998

24. Edmonds ME, Roberts VC, Watkins PJ (1982) Blood flow in the diabetic neuropathic foot. Diabetologia 22: 9-15

25. Ward JD, Simms JM, Knight G, Boulton AJM, Sandler DA (1983) Venous distension in the diabetic neuropathic foot (physical sign of arteriovenous shunting). J R Soc Med 76: 1011-1014

26. Boulton AJM, Scarpello JHB, Ward JD (1982) Venous oxygenation in the diabetic neuropathic foot: evidence of arteriovenous shunting? Diabetologia 22: 6-8

27. Tesfaye S, Harris N, Jakubowski J, Mody C, Ward JD (1990) Impaired blood flow and arterio-venous shunting in human diabetic sural nerve. Diabetic Med 7 [Suppl 2]:29A (Abstract)

28. Watkins PJ, Edmonds ME (1983) Sympathetic nerve failure in diabetes. Diabetologia 25: 73-77

29. Hunter GC, Song GW, Nayak NN, Zapotowski D, Guernsey JM (1988) Peripheral nerve conduction abnormalities in lower extremity ischaemia: the effects of revascularisation. J Surg Res 45: 96-103

Received: 15 June 1992

and in revised form: 4 August 1992

Dr. A.J.M. Boulton

Department of Medicine

Manchester Royal Infirmary

Oxford Road

Manchester M13 9WL

UK 